\title{
Controlled Brushless De-Excitation Structure for Synchronous Generators
}

\author{
Seif Eddine Chouaba \\ DAC-HR Laboratory, \\ Ferhat Abbas Setif University 1, \\ Setif, Algeria \\ seif.chouaba@univ-setif.dz
}

\author{
Abdallah Barakat \\ Electrical \& Computer Engineering Department, \\ Beirut Arab University, \\ Beirut, Lebanon \\ a.barakat@bau.edu.lb
}

\begin{abstract}
The main weakness of the brushless excitation system in a synchronous generator (SG) is the slow de-excitation response obtained during a load rejection. That is why voltage overshoots may be observed on the generator terminals. This behavior is mainly due to the exciter machine response time and the rotating diode bridge which is not able to quickly de-excite the generator by negative excitation voltages. This paper presents a new brushless de-excitation structure able to perform a quick de-excitation of the generator by providing controlled negative excitation voltage to the generator main field winding. The proposed structure is based on a new brushless de-excitation machine, called a control machine, and mounted on the same shaft of the generator and the brushless exciter. The brushless control machine is a low power one and used to transfer the orders from the voltage regulator to the discharge system located on the rotor side of the main generator. The dynamic performance of the proposed de-excitation system is evaluated in terms of system stability, voltage regulation response times and voltage overshoots during different load rejection tests. The proposed system is compared to the conventional brushless excitation system without the proposed de-excitation structure. In addition, a comparison is done with the static excitation system. The simulation tests are realized on an experimentally validated model of $11 \mathrm{kVA}$ synchronous generator developed in Matlab/Simulink.
\end{abstract}

Keywords-excitation system; synchronous generator; brushless excitation; static excitation; voltage regulation; feedback control systems

\section{INTRODUCTION}

Synchronous generators (SGs) are the most used machines in power generation. They are used in hydro, gas, steam and nuclear power plants. They are also used in diesel generators for hospitals, islands, electrical ships, etc. [1-4]. A good dynamic performance of the voltage regulation is required during small and large disturbances as full load rejection. Stability and performance of the voltage regulation depend mainly on the excitation system associated with the SG. The static excitation (SE) system presented in Figure 1 is commonly used in power plants. Its main advantage is the ability to control directly the field winding of the SG by positive and negative excitation voltages. Thus, static excitation system achieves high dynamic performances [5]. However, it is necessary to use a ring-brush system to transfer the power from the thyristor bridge located in the stationary part to the rotating part. In addition, the static excitation system includes heavy and bulky equipment with high current capability as the field current of generators is generally between 1000A and 8000A. The conventional brushless excitation (CBE) system presented in Figure 2 is widely used. It includes an exciter machine (EM) connected to an uncontrolled rotating diode bridge that excites the rotating field winding of the SG. Consequently, the CBE system does not need the ring-brush system used in static excitation systems to supply the SG field winding. The maintenance costs are then reduced. In addition, the power of the excitation equipment in the CBE system is small compared to the static excitation system as the excitation current of the exciter machine is generally less than $50 \mathrm{~A}$.

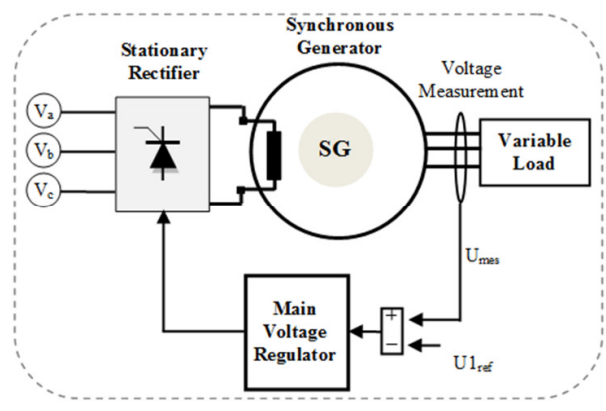

Fig. 1. Schematic of the SE system.

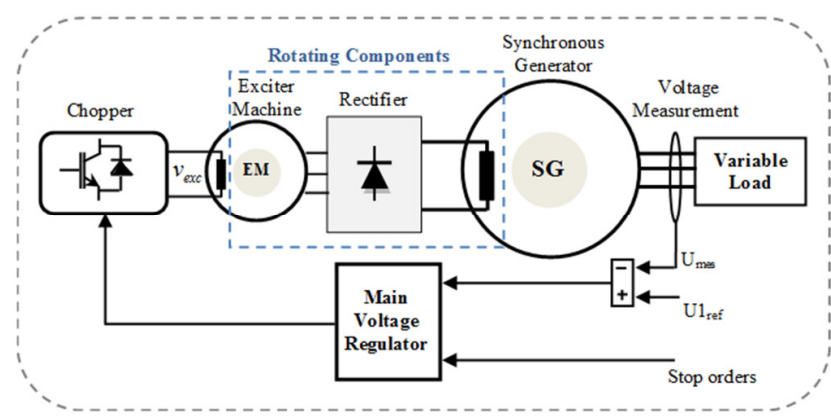

Fig. 2. Schematic of the CBE system 
Nevertheless, the main disadvantage of the CBE system is the impossibility to supply the field winding of the generator by negative excitation voltages which causes high voltage overshoot in the generator terminal during a full load rejection. Negative excitation voltages are needed to perform a fast deexcitation of the SG during a load rejection and stop orders (e.g. after a fault detection) [6-9]. Considerable efforts have been placed on the CBE system to improve the dynamic performances of SG. Voltage regulation with advanced digital controllers, sliding mode control, fuzzy logic controllers, $\mathrm{H}_{\infty}$ controllers, and neural network controllers achieves good performance and improves the transient stability of the closed loop system [10-14]. However, these advanced controllers have a minor effect in reducing the voltage overshoot and the response time during a load rejection. This is due to the rotating diode bridge which only provides positive excitation voltages to the SG field winding. Recently, many studies have been carried out on the optimization of the $\mathrm{CBE}$ power structure in order to provide negative excitation voltages. In [15], the negative excitation capability is obtained by self actuating deexcitation impedance located on the shaft. In other words, a fast demagnetization is obtained by short-circuiting the generator field winding with a discharge resistor mounted in parallel. However, the de-excitation system proposed in these researches cannot be controlled in a closed loop control strategy to improve the dynamics of the voltage regulation. Authors in $[16,17]$ proposed an excitation structure based on a rotating thyristor bridge. This solution allows controlling the generator field winding by negative and positive excitation voltages. The thyristor bridge control signal is transmitted from the stationary part to the rotating part by using wireless transmission techniques. This solution requires a robust transmission mode with respect to internal and external noises and perturbations. In this paper, a new brushless de-excitation structure which can be controlled in a closed loop is studied. The proposed structure associated with the conventional brushless excitation system is presented in Figure 3.

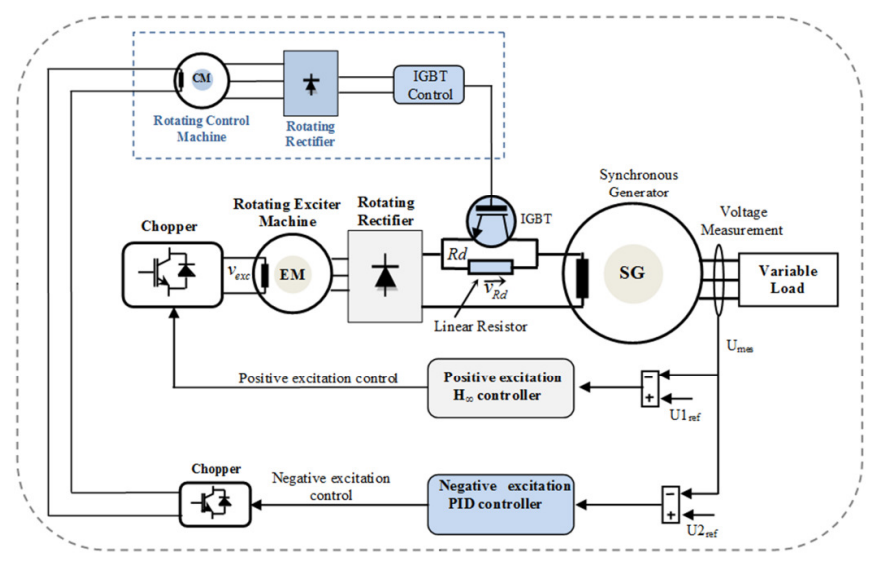

Fig. 3. Schematic of the ABE system

This advanced brushless excitation (ABE) can be used in new or refurbishment excitation projects. The de-excitation structure is based on a rotating IGBT mounted in parallel to a discharge resistor and controlled by a dedicated negative excitation controller via a rotating control machine. The openings of the rotating IGBT induce negative excitation voltages in the field winding and quickly de-excite the generator. In this paper, we will evaluate the performance of the new de-excitation structure with a PID negative excitation controller which is able to control continuously the rotating IGBT in steady and transient states. The influence of the resistance of the discharge resistor is also analyzed and presented. Using a realistic simulator, the $\mathrm{CBE}$ and $\mathrm{ABE}$ systems are tested and compared under a variety of operating conditions. In addition, a comparison is made with the static excitation system.

\section{DE-EXCITATION SYSTEM}

As presented in Figure 3, the proposed de-excitation structure includes the following:

- An IGBT located in the rotating part and mounted in series with the main field winding. The IGBT is sized to support the rated generator field current and the over-excitation current. In addition, during the opening of the IGBT, the voltage across the IGBT will be equal to the voltage across the discharge resistor. Consequently, the IGBT should support this induced voltage.

- A linear discharge resistor connected in parallel with the IGBT. The opening of the IGBT introduces the rotational discharge resistance $R_{d}$ and a negative excitation voltage across the field winding of the generator will then be applied. This helps in quickly demagnetizing the synchronous generator and allows the machine to react rapidly to over-voltage cases. The influence of the discharge resistance value, $R_{d}$, on the system stability and performances is studied in Section III.

- A control machine which is an inverted small power synchronous generator. This machine is used to transfer the order coming from the PID negative excitation to the rotating IGBT. The apparent power of the machine is very small because the connected load is only the driver of the IGBT.

- A small power DC chopper used to control the excitation current of the control machine current. It represents a converter from the PID orders to excitation voltage of the control machine.

- A negative excitation controller used to control the IGBT via the control machine. The controller selected is a PID one based on the supervision of the generator terminal voltage [18].

The CBE system with the main voltage regulator (positive excitation controller) is maintained to regulate the generator terminal voltage by controlling the generator field winding with positive voltages. The rotating IGBT can be controlled by two ways:

- Via a PWM signal controlled by the voltage output of the rectifier supplied by the control machine.

- Directly via the output voltage of the rotating rectifier connected to the control machine. 


\section{A. Negative Excitation Control Strategy}

The IGBT is controlled by a negative excitation controller based on the measured terminal voltage. The control strategy of the rotating IGBT is done by means of a proportional-integralderivative (PID) type regulator. Its control strategy is discussed below. In order to improve the transient performance in the presence of a voltage overshoot on the generator terminals, a negative excitation PID based controller for the rotating IGBT opening and closing control is set up. The PID regulator is widely used in industries and it does not require exact or precise modeling of the system as it is adjustable according to the application [19]. The PID law is given by:

$$
u_{P I D}(s)=P\left(1+I\left(\frac{1}{s}\right)+D\left(\frac{N s}{s+N}\right)\right)
$$

where $\mathrm{s}$ is the Laplace operator.

The PID regulator is described by four parameters. $P$ (proportional), I (integral), $D$ (differential), and $N$ (filter coefficient). The derivative term $D$ improves the dynamic performance by anticipating the opening of the rotating IGBT. The regulator input is the difference between the voltage reference value $\left(U 2_{r e f}\right)$ and the measured generator voltage $\left(U_{\text {mes }}\right)$. The PID parameters are adjusted to give a trade-off between the overvoltage overshoots and the response times. In this work, proportional and derivative constants are $P=100$ and $D=0.9$ respectively, and $N=700$. The voltage reference value of the PID is set equal to $105 \%$ of the generator rated voltage. During normal operation, the SG voltage is generally regulated to the rated value by the positive voltage regulator. Consequently, the PID output will saturate to " 1 " and the IGBT will be always ordered to close [18]. The IGBT is controlled to open during transient states when the terminal voltage tends to be higher than $105 \%$. The PID control scheme of the rotating IGBT is presented in Figure 4.

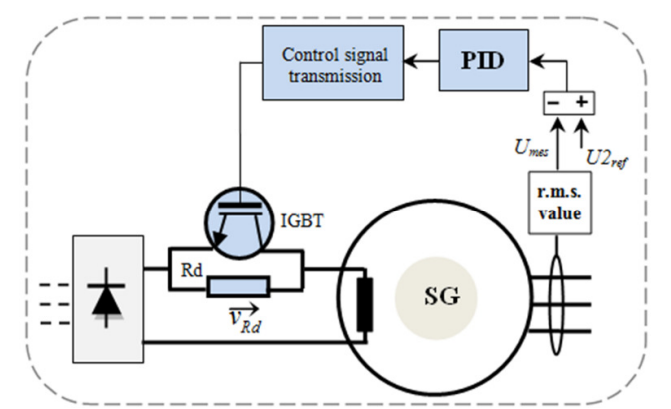

Fig. 4. Negative excitation control based on the PID regulator.

In this paper we make use of a low pass filter to simulate the system that transmits the orders from the PID regulator to the rotating IGBT. We present the closed loop system response during loads impact and shedding by considering the time constant of the low pass filter $\tau=2.5 \mathrm{~ms}$.

\section{B. Positive Excitation Control Strategy}

The positive excitation control strategy is the main control loop in $\mathrm{CBE}$ and $\mathrm{ABE}$ systems. The voltage reference of the controller is generally equal to the generator rated voltage. This controller operates during steady and transient states (loads impact and loads rejection). The PID regulator is widely used in industries [20]. Researchers validated the performances of advanced controllers (fuzzy logic, $\mathrm{H}_{\infty},[21,22]$ ). Based on the $\mathrm{H}_{\infty}$ control research done in [17], we designed an $\mathrm{H}_{\infty}$ regulator for the positive excitation in the $\mathrm{ABE}$ and the CBE systems. The system parameters and the reduced state space representation of the $\mathrm{H}_{\infty}$ regulator are given in the appendix. The $\mathrm{H}_{\infty}$ regulator considers the parameters of the $\mathrm{SG}$ and the excitation structure. The mathematical model of the system is given by the following equations:

$$
\begin{aligned}
v_{e x c}= & R_{e} i_{e x c}+L_{e} \frac{d i_{e x c}}{d t}-\left(k_{2} k_{3}\right) M_{s e} \frac{d i_{f}}{d t} \\
i_{d 1}= & i_{d p}+C_{1} \omega_{e p} v_{q p}-C_{1} \frac{d v_{d p}}{d t} \\
i_{q 1}= & i_{q p}-C_{1} \omega_{e p} v_{d p}-C_{1} \frac{d v_{q p}}{d t} \\
0= & -v_{d p}-R_{s} i_{d p}+L_{q} \omega_{e p} i_{q p}-M_{s Q} \omega_{e p} i_{Q}-L_{d} \frac{d i_{d p}}{d t} \\
& +M_{s f} \frac{d i_{f}}{d t}+M_{s D} \frac{d i_{D}}{d t} \\
0= & -v_{q p}-R_{s} i_{q p}-L_{d} \omega_{e p} i_{d p}+M_{s f} \omega_{e p} i_{f}+M_{s D} \omega_{e p} i_{D} \\
& -L_{q} \frac{d i_{q p}}{d t}+M_{s Q} \frac{d i_{Q}}{d t} \\
0= & -k_{1} M_{s e} \omega_{e e} i_{e x c}+a i_{f}+L_{f} \frac{d i_{f}}{d t} \\
- & M_{s f} \frac{d i_{d p}}{d t}+M_{f D} \frac{d i_{D}}{d t} \\
0= & R_{D} i_{D}+L_{Q}+L_{Q} \frac{d i_{D}}{d t}+M_{f D} \frac{d i_{f}}{d t}-M_{s D} \frac{d i_{d p}}{d t} \\
0 & \frac{d i_{q p}}{d t}
\end{aligned}
$$

This model has several parameters: $R_{e}$ and $L_{e}$ denote the resistance and the inductance respectively of the EM field winding, $R_{s}, L_{f}$ and $R_{f}$ are the SG stator resistance, field winding inductance and field winding resistance respectively, $L_{d}$ and $L_{q}$ are the direct and the transverse stator inductance, $R_{D}$, $R_{Q}, L_{D}$ and $L_{Q}$ are the direct and transverse dampers resistances, and the direct and transverse dampers inductances respectively, $M_{s f}$ and $M_{f D}$ are the mutual inductance between the direct stator winding and field winding and the mutual inductance between the field winding and the direct damper winding, $M_{s Q}$ and $M_{s D}$ are the mutual inductance between the direct stator winding and the transverse damper winding and the mutual inductance between the stator and the direct damper, $\omega_{e p}$ and $\omega_{e e}$ are the electrical angular speed of the $\mathrm{SG}$ and the EM, and $C_{l}$ represents a virtual three-phase capacitor added at the terminal of the SG to model the load current as a perturbation to be 
rejected by the voltage regulator. In addition, $a=k_{4} k_{3} L_{d e} \omega_{e e}+R_{f}$, where $k_{1}, k_{4}$ and $k_{3}$ are constants that depend on the EM parameters (leakage inductances, main inductance) and the operating mode of the rectifier. $k_{2}$ is a correction factor [17]. $i_{d 1}$ and $i_{q 1}$ are the load currents in $d q$ frame. $v_{e x c}$ and $i_{e x c}$ are the excitation voltage and the excitation current of the EM. The variables $v_{d p}, v_{q p}, i_{d p}$ and $i_{q p}$ are the generator voltages and currents in $d q$ fram, $i_{D}$ and $i_{Q}$ represent the direct and transverse dampers currents respectively, and $i_{f}$ denotes the current of the SG main field winding.

\section{VALIDATION AND PERFORMANCES ANALYSIS}

A realistic simulator, based on Matlab/Simulink, of the exciter machine, rotating diodes, and the synchronous generator was used [17]. The parameters of the SG and the EM are given in the Appendix. This section shows the validation of the $\mathrm{ABE}$ dynamic performance. $\mathrm{CBE}, \mathrm{SE}$, and $\mathrm{ABE}$ structures were tested. In addition, the influence of the discharge resistance value $R_{d}$ on the ABE system performances in closed loop will be shown. The performance of each system is evaluated during sudden load impact and shedding tests.

\section{A. Sudden Load Impact and Shedding Tests}

During the impact test, a load is suddenly connected to the unloaded SG. When the generator reaches its steady state, the shedding test is performed by removing the load. The active and reactive powers of the used loads are given in Table I. $P_{a}$ denotes the load active power, $S$ the apparent power, $Q$ the reactive power, and $P F$ the power factor. The value of the discharge resistor $R_{d}=3 R_{f}$ is chosen so that it does not stress the closed-loop behavior. $R_{f}$ is the resistance of the generator field winding.

TABLE I. USED LOAD DURING IMPACT/SHEDDING TESTS.

\begin{tabular}{|c|c|c|c|c|}
\hline Tests & $\boldsymbol{P}_{\boldsymbol{a}}(\mathbf{k W})$ & $\boldsymbol{S}(\mathbf{k V A})$ & $\boldsymbol{Q}(\mathbf{k V A R})$ & $\boldsymbol{P F}$ \\
\hline $100_{0.8}$ & 8.96 & 11.2 & 6.72 & 0.8 \\
\hline $100_{0.3}$ & 6.72 & 11.2 & 8.96 & 0.3 \\
\hline $100_{0.6}$ & 3.36 & 11.2 & 10.6 & 0.6 \\
\hline $150_{0.8}$ & 13.4 & 16.8 & 10 & 0.8 \\
\hline
\end{tabular}

In order to present clearly the systems responses, we will present the r.m.s. value of the terminal voltage (per unit). Figures 5-8 show the responses of the three systems (CBE, SE and $\mathrm{ABE}$ ) during load impact and shedding tests. The black curves refer to the system response using the CBE system, the red curves refer to the $\mathrm{ABE}$ system, and the blue dashed ones correspond to the SE structure. During load impact tests, the generator voltage drops due to the armature reaction of the generator. The positive voltage regulator increases the excitation currents to regulate the voltage at its rated value (1p.u.). The $\mathrm{CBE}$ and $\mathrm{ABE}$ systems give approximately the same results in terms of stability, voltage drop and response time. This is expected as the negative excitation controller presented in the ABE systems will not order the opening of the IGBT. The rotating IGBT is still closed during this transient. In the SE system, the voltage drop and the response time decrease. This expected result is related to the ability of the static excitation to control directly the generator field winding by positive and negative voltages. During load shedding tests and with the CBE system, the minimum excitation voltage that can be delivered to the generator field winding is zero. In addition, we should consider the response time of the exciter machine which reduces the dynamic of the system. This will increase the generator voltage overshoot and the system response time. However, in the ABE system, the opening of the rotating IGBT will directly introduce negative excitation voltages to the generator field winding. We can see that the ABE performance in terms of voltage overshoot and response time is better than the CBE's. This improvement is mainly related to the negative excitation system which de-excites fast the generator field winding. During the load shedding tests, we also see the good behavior of the static excitation in quickly stabilizing and regulating the SG voltage. The high negative ceiling voltage provided by the $\mathrm{ABE}$ system allows minimizing the peak voltage obtained on the SG terminals.

(a)

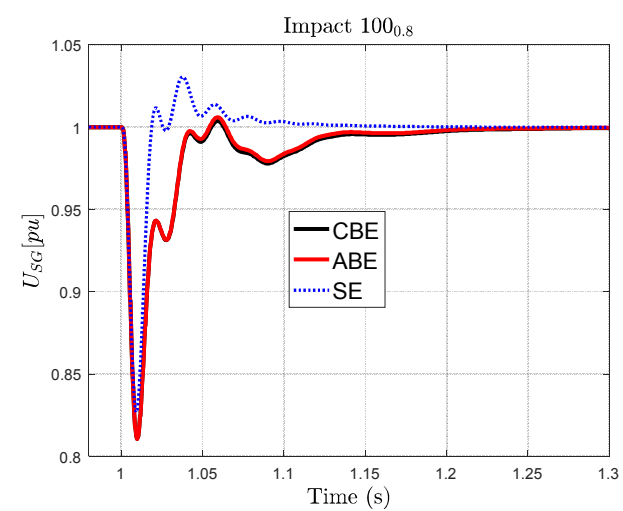

Shedding $100_{0.8}$

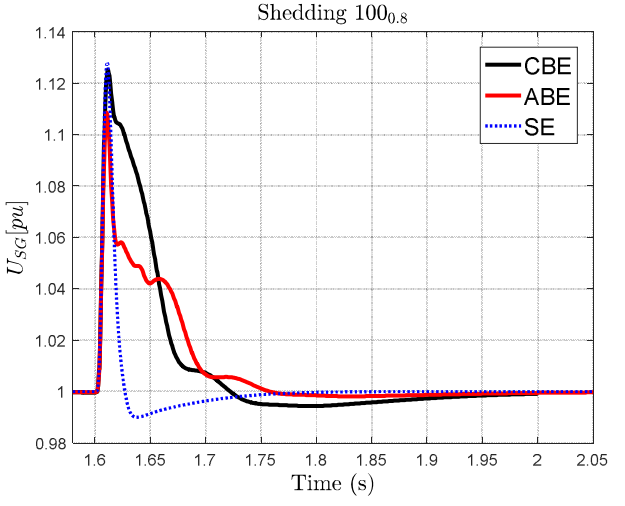

Fig. 5. Generator voltage (r.m.s.) during the (a) impact and (b) shedding test $\left(100_{0.8}\right)$

Table II shows a quantitative comparison between the results. $\Delta t_{s}(\mathrm{~ms})$ and $\Delta U_{s}(\%)$ are the response time and the voltage overshoot during load shedding tests. Note that the response time is measured at $0.5 \%$ of the set-point value. According to the different tests, the ABE system gives the overall better results. There is a minimization of the response time and the voltage overshoot during load shedding tests. For example, during the $100_{0.3}$ test, the voltage overshoot is about $10 \%$ using the ABE system and $15.1 \%$ using the CBE system. Regarding the response time, thanks to the $\mathrm{ABE}$ system, it is reduced from $350 \mathrm{~ms}$ to $146 \mathrm{~ms}$ (i.e. a ratio of 2.4 ). 
(a)
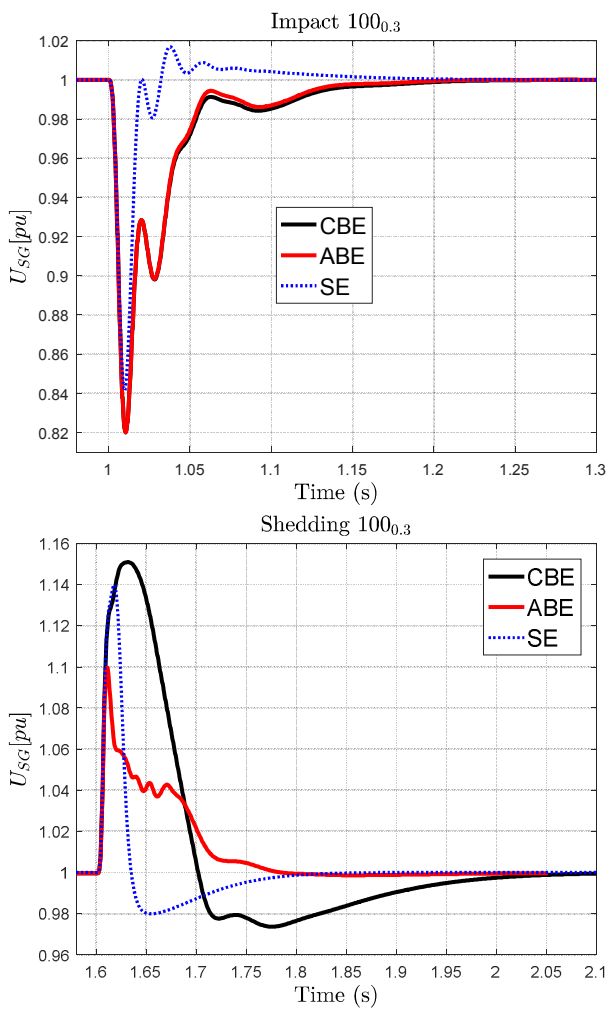

Fig. 6. Generator voltage (r.m.s.) during the (a) impact and (b) shedding test $\left(100_{0.3}\right)$

(a)

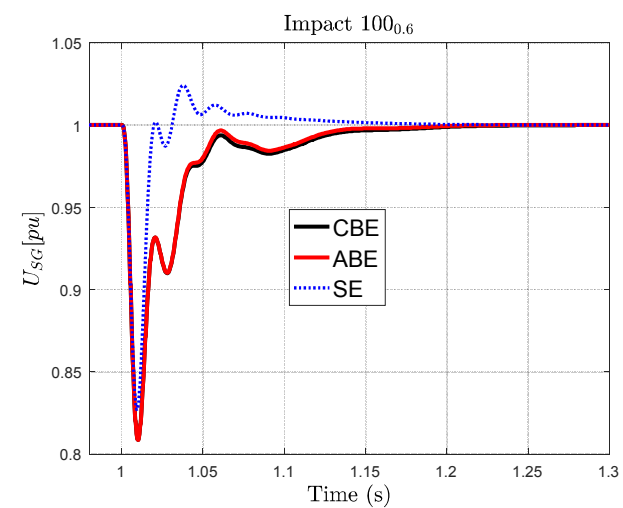

Shedding $100_{0.6}$

(b)

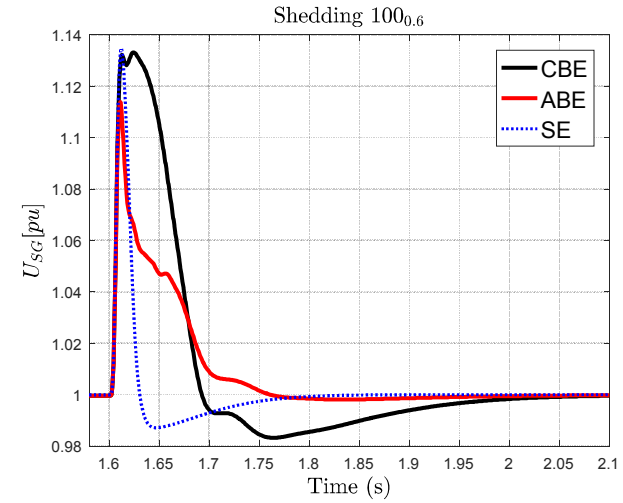

Fig. 7. Generator voltage (r.m.s.) during the (a) impact and (b) shedding test $\left(100_{0.6}\right)$ (a)

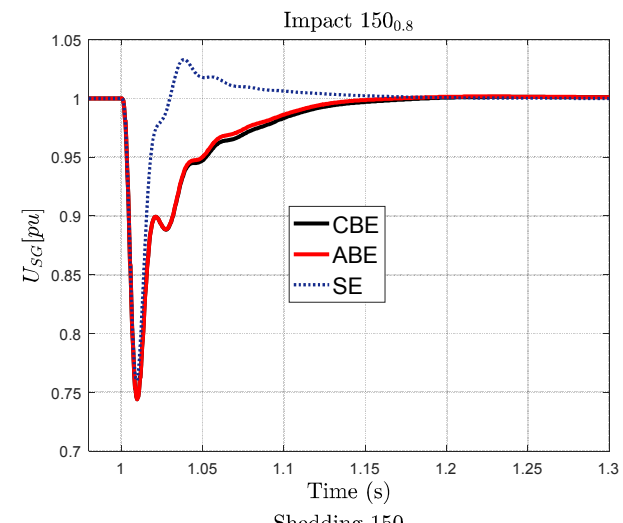

(b)

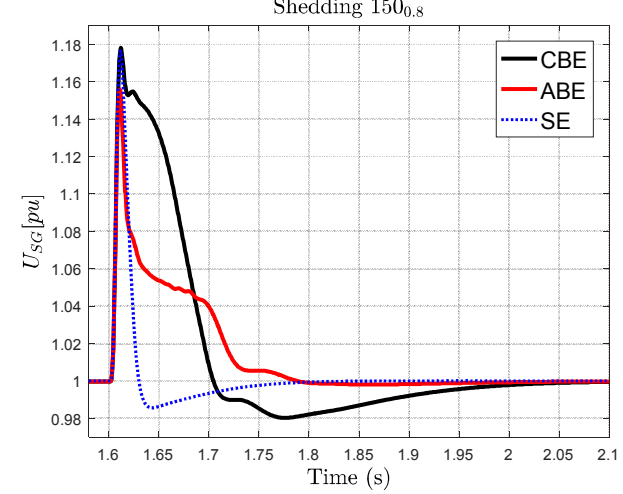

Fig. 8. Generator voltage (r.m.s.) during the (a) impact and (b) shedding test $\left(150_{0.8}\right)$.

TABLE II. RESULTS FOR LOAD SHEDDING TESTS.

\begin{tabular}{|c|c|c|c|c|c|c|c|c|}
\hline \multirow{2}{*}{$\begin{array}{c}\text { Shedding } \\
\text { Tests }\end{array}$} & \multicolumn{2}{|c|}{$\mathbf{1 0 0}_{\mathbf{0 . 8}}$} & \multicolumn{2}{c|}{$\mathbf{1 0 0}_{\mathbf{0 . 3}}$} & \multicolumn{2}{c|}{$\mathbf{1 0 0}_{\mathbf{0 . 6}}$} & \multicolumn{2}{|c|}{$\mathbf{1 5 0}_{\mathbf{0 . 8}}$} \\
\cline { 2 - 9 } & $\boldsymbol{\Delta} \boldsymbol{t}_{\boldsymbol{s}}$ & $\boldsymbol{\Delta} \boldsymbol{U}_{\boldsymbol{s}}$ & $\boldsymbol{\Delta} \boldsymbol{t}_{\boldsymbol{s}}$ & $\boldsymbol{\Delta} \boldsymbol{U}_{\boldsymbol{s}}$ & $\boldsymbol{\Delta} \boldsymbol{t}_{\boldsymbol{s}}$ & $\boldsymbol{\Delta} \boldsymbol{U}_{\boldsymbol{s}}$ & $\boldsymbol{\Delta} \boldsymbol{t}_{\boldsymbol{s}}$ & $\boldsymbol{\Delta} \boldsymbol{U}_{\boldsymbol{s}}$ \\
\hline CBE & 226 & 12.5 & 350 & 15.1 & 316 & 13.3 & 340 & 17.8 \\
\hline ABE & 130 & 10.8 & 146 & 10 & 130.3 & 11.4 & 160 & 15.6 \\
\hline SE & 85 & 12.8 & 175 & 14 & 172 & 13.4 & 171 & 17.6 \\
\hline
\end{tabular}

Figure 9 shows the evolution of the generator field voltage (i.e. excitation voltage of the SG field winding). In the CBE system, only positive excitation voltages can be provided. In the ABE system, when the IGBT opens, the negative forcing voltage quickly dissipates the SG field winding stored energy via the discharge resistor $R_{d}$. In the SE system, the thyristor bridge is able to deliver negative excitation voltages by controlling the firing angle to be around $155^{\circ}$. Figure 10 shows the field winding current evolution during de-excitation. It can be observed that the field current decay is much faster in the case of the ABE system.

\section{B. Influence of the Discharge Resistance Value}

By using the $\mathrm{ABE}$ system, it is possible to increase the speed of the de-excitation by increasing the discharge resistance $R_{d}$. However, very high negative voltages can stress the generator field windings. In this case, we must respect the maximum permissible insulation voltage of the generator field winding which is generally very high. Figures 11-14 illustrate the responses the $\mathrm{ABE}$ system for different values of $R_{d}\left(R_{d}=R_{f}\right.$, $R_{d}=3 R_{f}$ and $\left.R_{d}=6 R_{f}\right)$ and for different load impact and shedding tests $\left(100_{0.8}, 100_{0.3}, 100_{0.6}\right.$ and $\left.150_{0.8}\right)$. 


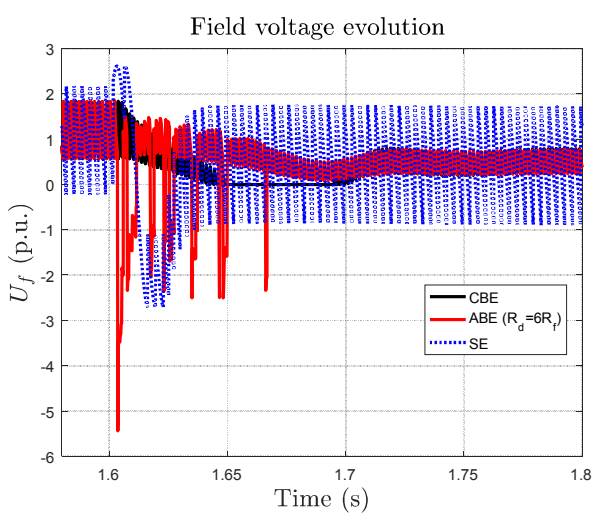

Fig. 9. Rotor voltage of the main generator (field voltage) of a load that consumes the $100 \%$ of the generator apparent power with a $0.3 P F$.

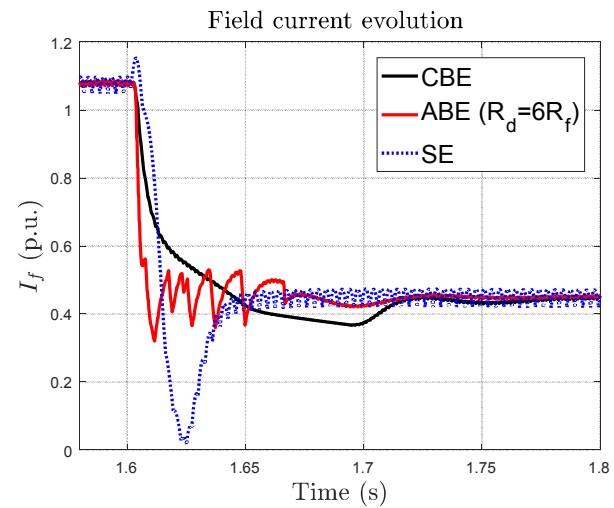

Fig. 10. Rotor current of the main generator (field current) of a load that consumes the $100 \%$ of the generator apparent power with a $0.3 \mathrm{PF}$.

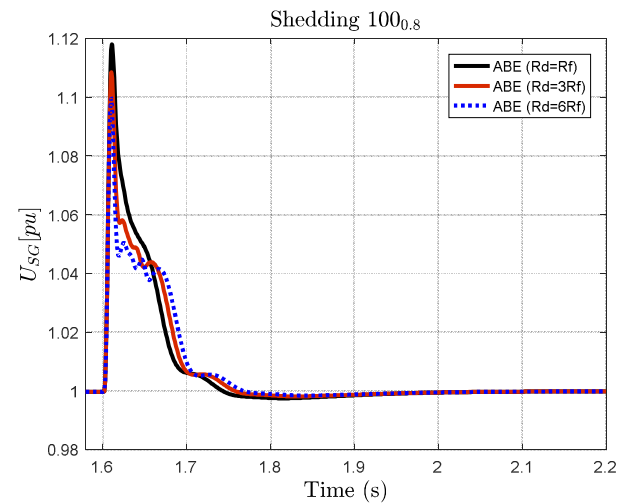

Fig. 11. $R_{d}$ influence during the shedding of the load $\left(100_{0.8}\right)$ with the PID negative excitation controller.

High discharge resistance values $R_{d}$ will reduce voltage overshoots during the load shedding tests because of the high negative voltage introduced in the generator field winding. However, a very high resistance value increases the dynamic of the system and may increase the oscillation amplitude in the generator voltage. During load impact tests, all structures give almost the same response. So, the value of the discharge resistor does not influence the closed-loop behavior because the rotating IGBT still closed during load impact tests.

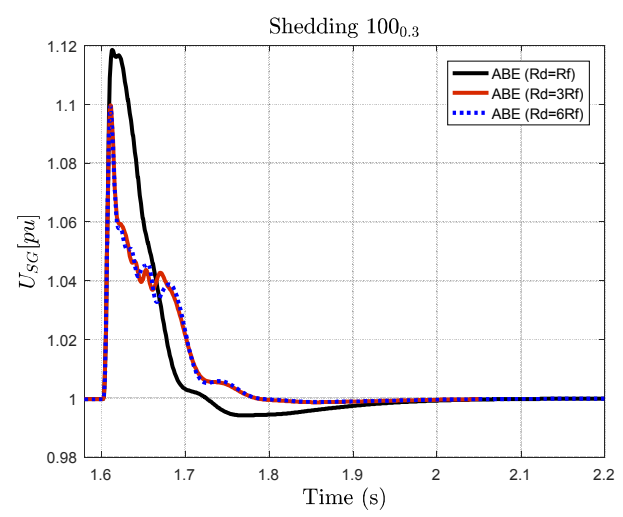

Fig. 12. $R_{d}$ influence during the shedding of the load $\left(100_{0.3}\right)$ with PID negative excitation controller.

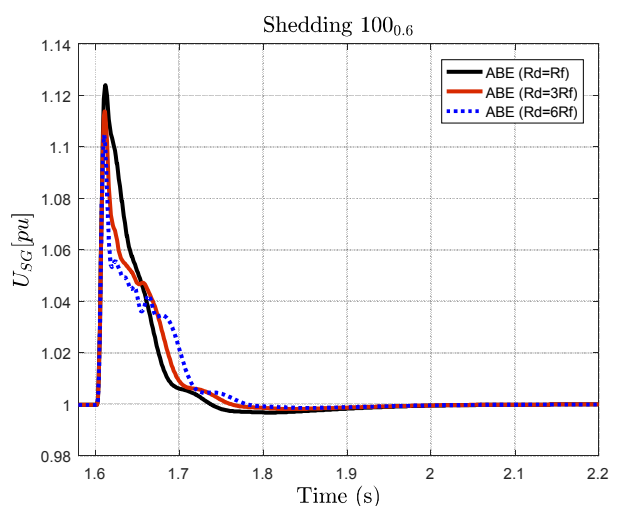

Fig. 13. $R_{d}$ influence during the shedding of the load $\left(100_{0.6}\right)$ with PID negative excitation controller.

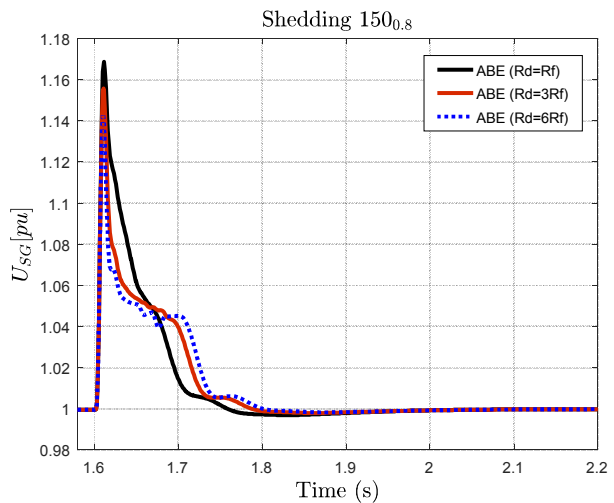

Fig. 14. $R_{d}$ influence during the shedding of the load $\left(150_{0.8}\right)$ with PID negative excitation controller.

\section{CONCLUSION}

This work presents a brushless de-excitation structure for brushless synchronous generators. The de-excitation structure can be controlled in static and transient states. In this paper, we compared the advanced brushless excitation system with conventional brushless and static excitation systems. The performance of each structure is presented by performing a sudden variation of the load connected to the main SG. The obtained results show that the proposed de-excitation structure maintains the system stability and improves the dynamic 
performance of the generator voltage regulation during load rejection tests. The quick dynamic de-excitation of the generator field winding reduces the terminal voltage overshoot and the response time. For example, during the shedding $100_{0.6}$ test, a considerable improvement in the response time and overshoot of the system response was observed. The response time for this test with ABE structure is $130 \mathrm{~ms}$ whereas it takes $316 \mathrm{~ms}$ with the CBE structure or 2.4 times longer than the ABE structure. Finally, the obtained results demonstrate the effectiveness of the proposed techniques and show good performance of the negative excitation PID controller in terms of system stability, voltage overshoot and response time.

APPENDIX

SG AND EM PARAMETERS

(RESISTANCES IN $\omega$, INDUCTANCES IN $\mathrm{mH}$ )

\begin{tabular}{|c|c|c|c|c|c|c|}
\hline \multicolumn{7}{|c|}{ Characteristics of the SG } \\
\hline Poles & $R_{s}$ & $R_{f}$ & $L_{f}$ & $L_{d}$ & $M_{s f}$ & $L_{q}$ \\
\hline 4 & 0.71 & 2.06 & 695 & 63.6 & 200.5 & 38.6 \\
\hline$L_{D}$ & $L_{Q}$ & $M_{f D}$ & $M_{s D}$ & $M_{s Q}$ & $R_{D}$ & $R_{Q}$ \\
\hline 0.0685 & 0.0236 & 6.7 & 2 & 0.9 & $8.6 \mathrm{e}-4$ & $9.9 \mathrm{e}-4$ \\
\hline \multicolumn{7}{|c|}{ Characteristics of the EM } \\
\hline Poles & $R_{s e}$ & $R_{e}$ & $L_{e}$ & $L_{d e}$ & $M_{s e}$ & $L_{q e}$ \\
\hline 8 & 0.26 & 24.5 & 1750 & 5.8 & 89 & 3.1 \\
\hline
\end{tabular}

\section{REFERENCES}

[1] M. Mirosevic, Z. Maljkovic, "Effect of Sudden Change Load on Isolated Electrical Grid", International Conference on Electrical Systems for Aircraft, Railway, Ship Propulsion and Road Vehicles, Aachen, Germany, March 3-5, 2015

[2] I. Boldea, "Electric generators and motors: an overview", CES Transactions on Electrical Machines and Systems, Vol. 1, No. 1, pp. 314,2017

[3] G. G. Gutierrez, D. M. Romero, M. R. Cabello, E. Pascual-Gil, L. D. Angulo, D. G. Gomez, S. G. Garcia, "On the design of aircraft electrical structure networks", IEEE Transactions on Electromagnetic Compatibility, Vol. 58, No. 2, pp. 401-408, 2016

[4] B. Stevens, A. Dubey, S. Santoso, "On improving reliability of shipboard power system”, IEEE Transactions Power Systems, Vol. 30, No. 4, pp. 1905-1912, 2015

[5] J. K. Noland, M. Giset, F. Alves, "Continuous Evolution and Modern Approaches of Excitation Systems for Synchronous Machines", XIII International Conference on Electrical Machines, Alexandroupoli, Greece, September 3-6, 2018

[6] R. C. Schaefer, "Applying static excitation systems", IEEE Industry Applications Magazine, Vol. 4, No. 6, pp. 41-49, 1998

[7] J. Taborda, "Modern Technical Aspects of Field Discharge Equipment for Excitation Systems", IEEE Power and Energy Society General Meeting-Conversion and Delivery of Electrical Energy in the 21st Centuty, Pittsburgh, USA, July 20-24, 2008

[8] C. A. Platero, M. Redondo, F. Blazquez, P. Frias, "High-speed deexcitation system for brushless synchronous machines", IET Electric Power Application, Vol. 6, No. 3, pp. 156-161, 2012

[9] A. Barakat, S. Tnani, G. Champenois, E. Mouni, "Output voltage control of synchronous generator using diode and thyristor excitation structures combined with multivariable $\mathrm{H}_{\infty}$ controllers", IET Electric Power Applications, Vol. 6, No. 4, pp. 203-213, 2012

[10] D. M. Sajnekar, S. B. Deshpande, R. M. Moharil, "Efficient PID Controller Tuning Method Selection to be Used in Excitation System of Brushless Synchronous Generator", International Conference on Computation of Power, Energy Information and Communication, Chennai, India, April 20-21, 2016
[11] N. M. Guan, W. Pan, J. Zhang, Q. Hao, J. Cheng, X. Zheng, "Synchronous generator emulation control strategy for voltage source converter (VSC) stations", IEEE Transactions on Power Systems, Vol. 30, No. 6, pp. 3093-3101, 2015

[12] H. Zhang, F. Shi, Y. Liu, "Enhancing optimal excitation control by adaptive fuzzy logic rules", International Journal of Electrical Power and Energy Systems, Vol. 63, pp. 226-235, 2014

[13] E. Swidenbank, S. Mcloone, D. Flynn, G. W. Irwin, M. D. Brown, B. W. Hogg, "Neural Network Based Control for Synchronous Generators", IEEE Transactions on Energy Conversion, Vol. 14, No. 4, pp. 16731678,1999

[14] R. L. A. Ribeiro, C. M. S. Neto, F. B. Costa, T. O. A. Rocha, R. L. Barreto, "A sliding-mode voltage regulator for salient pole synchronous generator", Electric Power Systems Research, Vol. 129, pp. 178-184, 2015

[15] E. Rebollo, C. A. Platero, F. Blazquez, R. Granizo, "Internal sudden short-circuit response of a new hsbds for brushless synchronous machines tested on a 15 MVA generator", IET Electric Power Applications, Vol. 11, No. 4, pp. 495-503, 2017

[16] F. Bensmaine, A. Barakat, S. Tnani, G. Champenois, E. Mouni, "Dual control of synchronous generator for terminal voltage regulationcomparison with a single control", Electric Power System Research, Vol. 91, No. 1, pp. 78-86, 2012

[17] A. Barakat, S. Tnani, G. Champenois, E. Mouni, "Monovariable and multivariable voltage regulator design for a synchronous generator modeled with fixed and variable loads", IEEE Transactions on Energy Conversion, Vol. 26, No. 3, pp. 811-821, 2011

[18] A. Barakat, S. Chouaba, "Performance Improvement of Brushless Generator Voltage Regulation by Using a Controlled Non Linear Discharge Resistor", XXIII International Conference on Electrical Machines, Alexandroupoli, Greece, September 3-6, 2018

[19] K. J. Astrom, T. Hagglund, PID Controllers: Theory, Design, and Tuning, Instrument Society of America, 1995

[20] K. Kim, R. C. Schaefer, "Tuning a pid controller for a digital excitation control system", IEEE Transactions on Industry Applications, Vol. 41, No. 2, pp. 485-492, 2005

[21] M. Gunes, N. Dogru, "Fuzzy control of brushless excitation system for steam turbogenerators", IEEE Transactions on Energy Conversion, Vol. 25, No. 3, pp. 844-852, 2010

[22] E. Mouni, S. Tnani, G. Champenois, "Synchronous generator output voltage real-time feedback control via ho strategy", IEEE Transactions on Energy Conversion, Vol. 24, No. 2, pp. 329-337, 2009

\section{AUTHORS PROFILE}

Seif Eddine Chouaba received his $\mathrm{PhD}$ degree in automatic control from the University of Poitiers, France, in 2012. He is an assistant professor at Ferhat Abbas University, Setif, Algeria. His main research interests include linear parameter-varying systems identification and modeling of heat exchangers. His current activities focus on modeling and control of electrical machines and static converters.

AbdAllah Barakat received his PhD in 2011 from the University of Poitiers (France). He is an assistant professor at Beirut Arab University in Lebanon. He worked at General Electric as principal engineer for 6 years in control of hydropower plants. His major research interests include modeling and control of electrical machines, power systems and static converters. 